\title{
Seismic hazard assessment for the Caucasus test area
}

\author{
Serguei Balassanian $\left({ }^{1}\right)$, Tahmet Ashirov $\left({ }^{2}\right)$, Tamaz Chelidze $\left({ }^{3}\right)$, Arieev Gassanov $\left({ }^{4}\right)$, \\ Nadia Kondorskaya $\left({ }^{5}\right)$, George Molchan $\left({ }^{6}\right)$, Bella Pustovitenko $\left({ }^{7}\right)$, Vladimir Trifonov $\left({ }^{5}\right)$, \\ Valentin Ulomov $\left({ }^{5}\right)$, Domenico Giardini $\left({ }^{8}\right)\left({ }^{9}\right)$, Mustafa Erdik $\left({ }^{10}\right)$, \\ Mohsen Ghafory-Ashtiany $\left({ }^{11}\right)$, Gottfried Grünthal $\left({ }^{12}\right)$, Dieter Mayer-Rosa $\left({ }^{9}\right)$, \\ Vladimir Schenk $\left({ }^{13}\right)$ and Max Stucchi $\left({ }^{14}\right)$ \\ (') National Survey for Seismic Protection, Yerevan, Armenia \\ $\left.{ }^{2}\right)$ Institute of Seismology, Academy of Sciences, Ashkhabad, Turkmenistan \\ $\left(^{3}\right)$ Institute of Geophysics, Academy of Sciences, Tbilisi, Georgia \\ $\left({ }^{4}\right)$ Experimental Methodical Geophysical Expedition, Academy of Sciences, Baku, Azerbaijan \\ $\left(^{5}\right)$ Joint Institute of Physics of the Earth, Moscow, Russia \\ $\left(^{6}\right)$ International Institute of Earthquake Prediction Theory and Mathematical Geophysics, Moscow, Russia \\ $\left(^{7}\right)$ Geophysics Institute, National Academy of Sciences, Kiev, Ukraine \\ $\left.{ }^{8}\right)$ Istituto Nazionale di Geofisica, Roma, Italy \\ ${ }^{9}{ }^{9}$ Institute of Geophysics, ETH Zurich, Switzerland \\ $\left({ }^{10}\right)$ Bogazici University, Kandilli Observatory, Istanbul, Turkey \\ ${ }^{(11)}$ International Institute of Earthquake Engineering and Seismology, Teheran, Iran \\ ${ }^{12}$ ) GeoForschungsZentrum, Potsdam, Germany \\ $\left({ }^{13}\right)$ Institute of Rock Mechanics, Academy of Sciences, Prague, Czech Republic \\ $\left.{ }^{14}\right)$ Istituto di Ricerca sul Rischio Sismico, Milano, Italy
}

\begin{abstract}
The GSHAP CAUCAS test area was established under the INTAS Ct.94-1644 (Test Area for Seismic Hazard Assessment in the Caucasus) and NATO ARW Ct.95-1521 (Historical and Prehistorical Earthquakes in the Caucasus), with the initial support of IASPEI, UNESCO and ILP. The high tectonic interest and seismicity rate of the whole area, the availability of abundant multi-disciplinary data and the long established tradition in hazard assessment provide a unique opportunity to test different methodologies in a common test area and attempt to establish some consensus in the scientific community. Starting from the same input data (historical and instrumental seismic catalogue, lineament and homogeneous seismic source models) six independent approaches to seismic hazard assessment have been used, ranging from pure historical deterministic to seismotectonic probabilistic and areal assessment methodologies. The results are here compared.
\end{abstract}

Key words seismic hazard assessment-historical earthquakes - active faults - Caucasus - UN/IDNDR

Mailing address: Dr. Serguei Balassanian, National Survey for Seismic Protection, Yerevan, Armenia; e-mail: presidnt@nssp.r.am

\section{Introduction}

The Caucasus is one of the most active segments of the Alpine-Himalayan seismic belt and marks the junction between the African, Arabian and Indian plates to the south, and Eurasian continent to the north (fig. 1). Vulnerability to disaster is increasing in the Caucasus as urban- 


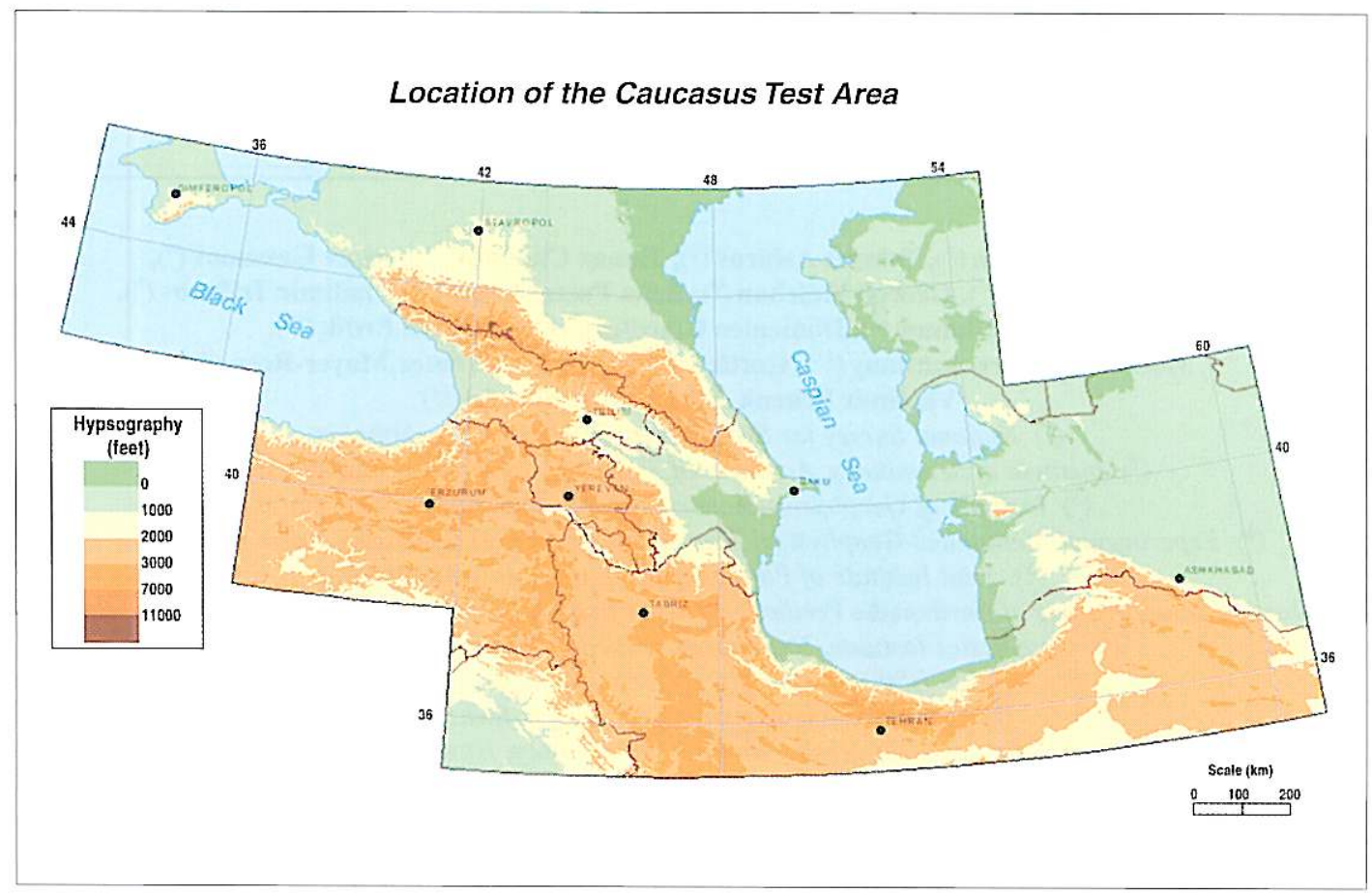

Fig. 1. Geographical and political map of the Caucasus-Kopetdagh region.

ization and developments occupy more areas that are prone to the effects of significant earthquakes, as demonstrated in the last few years by the devastating earthquakes in Turkey, 1976 and 1983; Armenia, 1988; Iran, 1990 and 1997; Georgia, 1991; Turkey and Georgia, 1992.

The Caucasus is considered a key area for seismic hazard assessment by the whole geophysical community; IASPEI, ESC and GSHAP have agreed to concentrate efforts in the Caucasus in the 1994-1997 period for the following reasons:

- The high tectonic interest and seismicity rate of the whole area, the availability of abundant multi-disciplinary data and the long established tradition in hazard assessment provide a unique opportunity to test different methodologies in a common test area and attempt to establish some consensus in the scientific community.
- European scientists have a keen interest in the Caucasus for the expected return for European science as the geodynamic framework of the Mediterranean depends on the Caucasus tectonic junction; understanding the seismic cycle here would improve the regional hazard assessment.

- Assist national efforts and avoid the disruption of the existing scientific and co-operative infrastructure in the Caucasian region and to improve co-operation with Iran and Turkey, fostering an across-boundaries approach to hazard assessment.

The last task is particularly urgent since at the time of breakdown of the U.S.S.R., large differences in hazard assessment approaches and in national seismic zonations already existed at the State boundaries of the former U.S.S.R., Iran and Turkey (fig. 2).

The GSHAP CAUCAS test area was established with the initial support of IASPEI, 
UNESCO and ILP; the INTAS Ct.94-1644 (Test Area for Seismic Hazard Assessment in the Caucasus) and NATO ARW Ct.95-1521 (Historical and Prehistorical Earthquakes in the Caucasus; Giardini and Balassanian, 1997) provided the resources needed to carry out the work, with the participation of specialists from Caucasus countries and from Western Europe: Armenia (National Survey for Seismic Protection of RA, NSSP, Yerevan); Georgia (Institute of Geophysics, Georgian Academy of Sciences, IG/ GAS Tbilisi); Azerbaijan (Experimental Methodical Geophysical Expedition of the Azerbaijan Academy of Sciences, EMGE, Baku); Iran (International Institute of Earthquake Engineering and Seismology, IIEES, Tehran); Turkey (Bogazici University, Kandilli Observatory, BUKO; Earthquake Research Institute, ERI, Istanbul);
Russia (Joint Institute of Physics of the Earth, JIPE; International Institute of Earthquake Prediction Theory and Mathematical Geophysics, MITPAN, Moscow); Ukraine (Geophysics Institute, National Academy of Sciences of Ukraine, IG/NAS, Kiev); Turkmenistan (Institute of Seismology, Turkmenistan Academy of Sciences, IS/TAS, Ashkhabad); Italy (Istituto Nazionale di Geofisica, ING, Rome); Germany (GeoForschungZentrum, GFZ, Potsdam); Switzerland (ETH, Institute of Geophysics, IG/ETHZ, Zurich).

The work was conducted in close coordination and with the technical support of the GSHAP Regional Center at UIPE, Moscow; more details on the hazard assessment for the whole area are given by Ulomov (1999). Four main tasks were identified and carried out by working groups, formed by specialists from the Cauca-

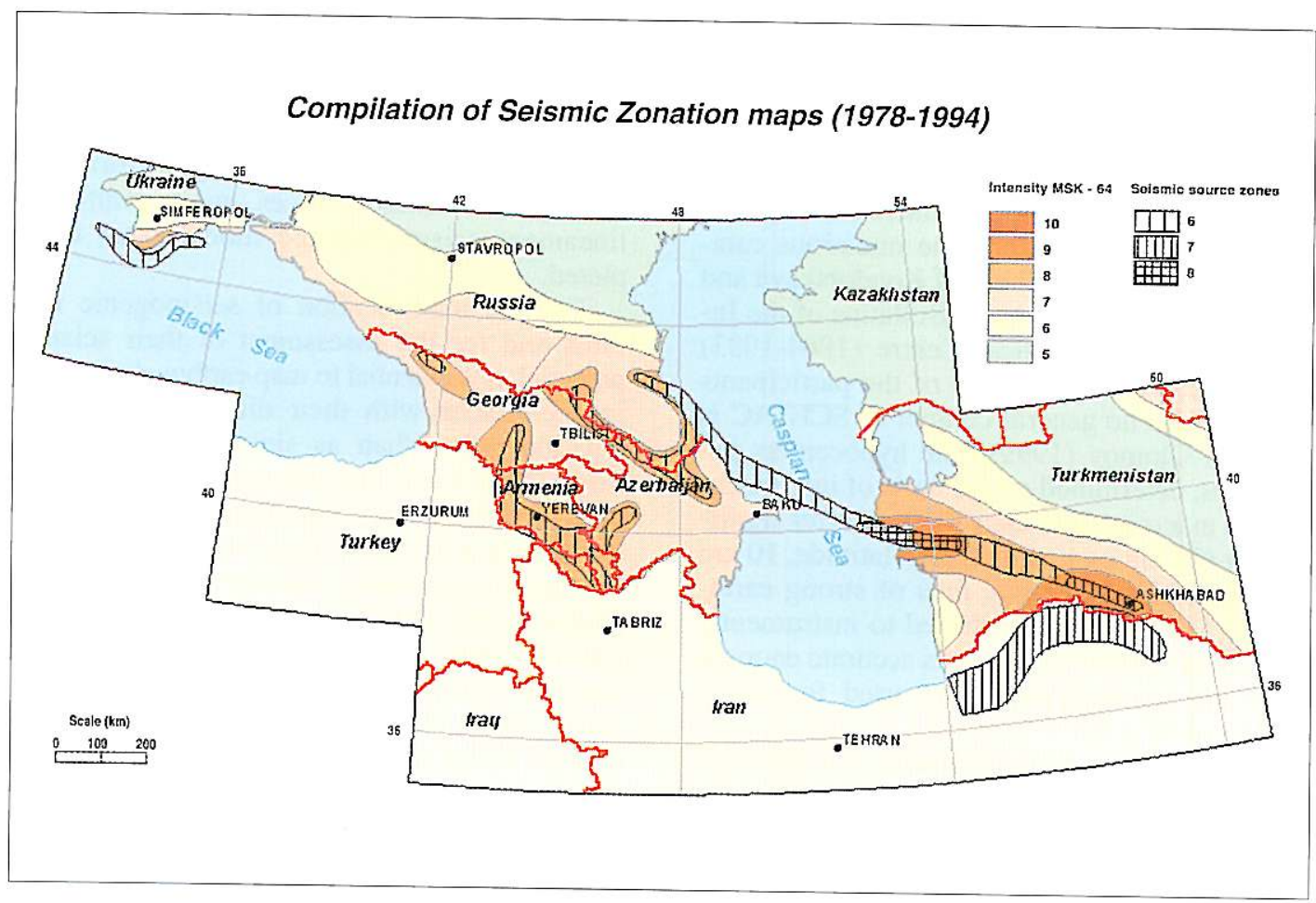

Fig. 2. Compilation of existing seismic zonation maps in the Caucasus-Kopetdagh region before the start of this project. According data of earthquake zonation maps: territory of the former Soviet Union («OSR-78»), editors V.I. Bune and G.P. Gorshkov (1980); territory of Turkey, after P. Gulkan and M. Yucemen (1991); territory of
Iran, after A. Moinfar et al. (1988). 
sus, Iran, Turkey, FSU and Western Europe: 1) earthquake catalogue and database; 2) seismic source zoning; 3) strong seismic ground motion; 4) seismic hazard mapping. The Steering Committee of the Caucasus test area met six times, to evaluate progress and planning, in Ashkhabad, 10/94; Tehran, 5/95; Boulder, 7/95; Erice, 10/95; Yerevan, 7/96; Tbilisi, 7/97.

\section{Earthquake catalogue and database}

Under the leadership of N. Kondorskaya at JIPE, Moscow, the Special Catalogue of Earthquakes for the CAUCAS Test Area (SCETAC) was compiled by the Catalogue Working Group. The epicentral map is shown in fig. 3. The catalogue covers three time periods:

- 2000 B.C.-1899, pre-instrumental.

- 1900-1963, early instrumental.

- 1964-1993, modern instrumental.

The catalogue for the pre-instrumental period was extracted from Shebalin and Tatevossian (1997). For the instrumental period, the earthquake parameters have been compiled on the basis of a joint analysis of macro-seismic and instrumental data. Among the numerous catalogues included were those of Kondorskaya and Shebalin (1982), the yearly Bulletins of the International Seismological Centre (1964-1993) and the national catalogues of the participants in the WG. The general content of SCETAC is given in Ulomov (1999). The hypocenters parameters, determined on the basis of instrumental and macroseismic data, did not differ significantly $(20 \mathrm{~km}$ on longitude and latitude, $10 \mathrm{~km}$ on depth). Macroseismic data of strong earthquakes $(M \geq 6)$ were preferred to instrumental data if the isoseismal map was accurate enough. Only instrumental data were used for earthquakes of $M<6$.

The following main parameters are listed by SCETAC: origin time, epicentre co-ordinates, depth, magnitude, epicentral intensity. Each parameter is followed by its reference number and a descriptor which indicates the parameter determination method. The catalogue also contains identifiers of event type and earthquake associated phenomena, as well as Flinn-Engdahl region and country code number.
Two type of magnitudes were used in SCETAC: conventional magnitude $(M)$ and moment magnitude $\left(M_{\mathrm{W}}\right)$. The conventional magnitude for larger events was determined using surface waves and the Prague formula (Karnik et al., 1962); $M=M_{s}$ for $M_{s} \geq 5.3$. For smaller magnitudes, it was calculated on the basis of $K$ energetic classes, using the correlation function between $M$ and $K$ by Rautian (1960): $M=0.55$ $K-2.2$. The moment magnitude was computed with the equation of Hanks and Kanamori (1997): $M_{W}=2 / 3 \log M_{0}-10.7$. The direct assessment of the seismic moment was made using $P$ wave spectra as well as from the centroid moment tensors from Harvard University.

In the compilation of SCETAC, aftershocks and foreshocks were identified and purged in the magnitude range $M=2.0-8.0$.

\section{Seismic source zoning}

Under the leadership of V. Ulomov at JIPE, Moscow, the preparation of all geophysical/ geological input materials in digital form and of maps of seismic sources, active faults and lineament seismic source model were completed.

For the identification of seismogenic features and for the assessment of their seismic potential, it is essential to map earthquake sources in accordance with their dimension and orientation rather than as simple point-sources. These parameters are determined from several data sets: aftershock distribution, surface ruptures, higher intensity isoseismals, earthquake mechanisms, geodetic measurements, tectonic analyses, etc. The lineament model of Seismic Source Zones was compiled by the Working Group on Seismic Source Zoning in 1996 and is shown in fig. 4. The thickness of the lines decreases twice with each reduction step of the magnitude value. The value of maximum potential magnitude for each lineament $\left(M_{\max }\right)$ is estimated from the dimensions of paleo-ruptures, archaeological and historical remains, the width of zones of dynamic influence of seismogenetic features, the lengths of seismogenic faults and lineaments, the dimensions of interacting geoblocks, the location of bends in recurrence 


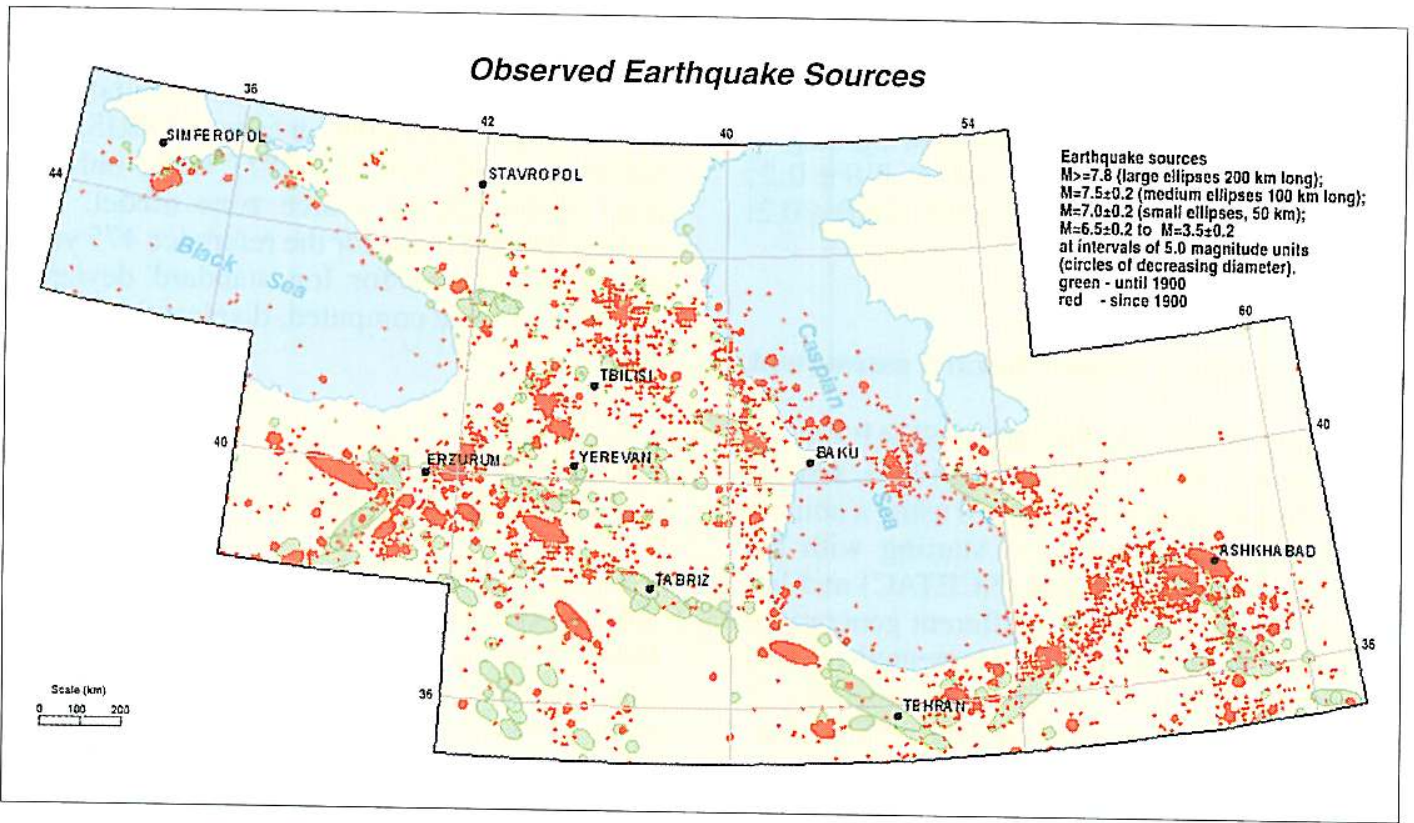

Fig. 3. Earthquake location from the SCETAC catalogue. Different symbols are plotted according to event size; for larger earthquakes the symbol scales with the event fault area (see legend and text).

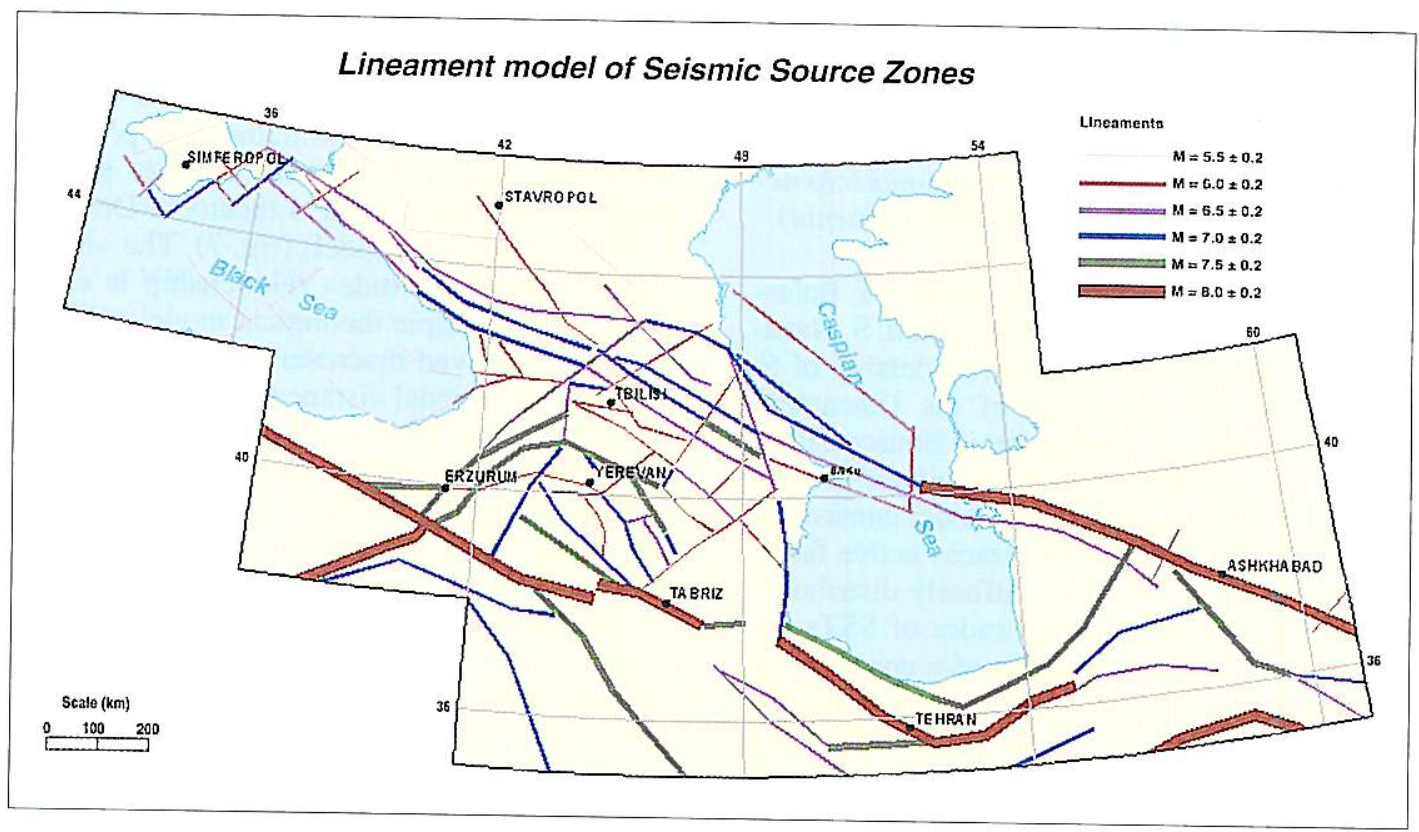

Fig. 4. Lineament model of seismic source zones. The thickness of the lines decreases twice with each step of reduction of the magnitude value. Lineament source zones are classified, similarly to earthquakes, according to the maximum potential magnitude they are capable to generate (more details in text and in the legend). 
curves, extreme values in the plot of accumulated strain in earthquake-generating features. Lineament source zones are classified, similarly to earthquakes, according to the following magnitude groups $\left(M_{S}\right.$ or $\left.M_{W}\right): M \leq 8.0 \pm 0.2$; $\leq 7.5 \pm 0.2 ; \leq 7.0 \pm 0.2 ; \leq 6.5 \pm 0.2 ; \leq 6.0 \pm 0.2$; $\leq 5.5 \pm 0.2$.

\section{Multi-method seismic hazard assessment}

Following the IASPEI and GSHAP recommendations for the CAUCAS test area, seismic hazard assessment was compiled using a number of different techniques and starting with the same earthquake catalogue (SCETAC) and lineament source model. Six different generations of hazard mapping were implemented by four independent groups:

- Seismotectonic-probabilistic, NSSP, Yerevan, Armenia.

- Deterministic-probabilistic, JIPE, Moscow, Russia.

- Aereal probabilistic, MITPAN, Moscow, Russia.

- Deterministic, probabilistic, historicalprobabilistic, IG/GAS, Tbilisi, Georgia.

\subsection{Seismic hazard assessment: seismotectonic- probabilistic approach (NSSP, Armenia)}

This mapping was implemented by S. Balassanian, A. Martirosyan, A. Avanessian, S. Nazaretian, A. Arakelian, under the leadership of S. Balassanian. On the basis of the Lineament model of SSZs the areal Seismic Source Zones Model was composed for probabilistic assessment of seismic hazard. This model consists of zones, each of which either traces active faults or represents an area with diffusely distributed seismicity. Maximum magnitudes of SSZs are mainly defined by magnitude of a corresponding seismotectonic structure, varying within its uncertainty depending on the magnitude of the strongest earthquake of that zone. Using spatial interpolation and a smoothing procedure, a map of mean hypocentral depths is compiled and all the zones are divided into three groups with mean depths of 10,15 and $20 \mathrm{~km}$. The ground motion attenuation model of Joyner and Boore (1993), used before for seismic hazard computations in Armenia, was adopted. Calculation of accelerations was done using SEISRISK III by Bender and Perkins (1987), using only the areal homogeneous source zone model. Two seismic hazard maps for the reference 475 years return period and for $\log$ standard deviation 0.5 and 0.6 were computed, displayed in figs. 5 and 6 .

\subsection{Seismic hazard assessment: deterministic- probabilistic approach (JIPE, Russia)}

This mapping was implemented by V. Ulomov, A. Gusev, V. Pavlov, L. Shumilina and N. Medvedeva under the leadership of V. Ulomov. The methodology for seismic hazard assessment is based on the concept of structural-dynamic unity of the medium and on a deterministic-probabilistic approach to hazard assessment. This methodology includes three-dimensional source zones and adequately reflects the nature of seismicity. The authors considered four structural levels of seismic source zones; the main structural unit of global seismicity is the region, which includes three types of seismic structure; lineaments, domains and potential earthquake sources. All these features are the main components of the Lineament-DomainFocal model (LDF-model) (fig. 7). The «intensity-distance-magnitude» relationship is simulated using a simple theoretical model calibrated using observed macroseismic data from the test area; at regional distances, it coincides with the average $I(r, \mathrm{MLH})$ relationships after Shebalin, derived for the Caucasus and for the whole of Eurasia; in the vicinity of the source, instead, the Blake-Shebalin formula overestimates intensity.

The model we adopt eliminates this inconsistency and describes the amplitude saturation around a fault. To calculate seismic hazard maps, an algorithm and software were designed, which mainly follow the common lines of Riznichenko (1965) and Cornell (1968). Two hazard versions were compiled, the first with an upper boundary of earthquake sources constant over the whole territory of the test area, located within the su- 
perficial $5 \mathrm{~km}$ thick layer, the second with the upper boundary of earthquake sources also $5 \mathrm{~km}$ thick, but starting below the unconsolidated sediment layers. This version is more realistic (fig. 8).

\subsection{Seismic hazard assessment: areal- probabilistic approach (MITPAN, Russia)}

This mapping was implemented by G. Molchan, T. Kronrod, A. Gorshkov, A. Nekrasova under the leadership of G. Molchan. The seismic source zones map is based on the idea of a multifractal representation for the GutenbergRichter frequency-magnitude law. The idea requires that the seismotectonic regionalization be carried out at several scales, using a morphostructural zoning of the region, derived from the data on active faults of Trifonov and Machette (1993) and a general map of major lineaments. The ground motion attenuation model of Caputo and Molchan was used, valid for medium soils and normal-depth earthquakes. For the computation they used a special version of the universal algorithm by Keilis-Borok et al. (1973), developed to assess economic and other risks related to earthquake hazard. Figure 9 displays areas with expected shaking of intensity $I \geq$ VI, VII, VIII, IX with a return period of 475 years.

\subsection{Seismic hazard assessment: deterministic approach (IG/GAS, Georgia)}

The deterministic map of seismic hazard was compiled by Z. Javakhishvili, O. Varazanashvili, N. Butikashvili under the leadership of Z. Javakhishvili. Maximum expected intensities (MSK) are shown in fig. 10. The map was compiled on the basis of the map of seismic source zones of the Caucasus test area, which, in its turn, was based on the map of the lineament model of SSZs. The transition from the map of SSZs to the deterministic map of seismic hazard was implemented on the basis of the generalized elliptic models of isoseismals.

\section{Seismic hazard assessment: probabilistic approach (IG/GAS, Georgia)}

A second generation of probabilistic hazard was compiled by Z. Javakhishvili, O. Varazanashvili and N. Butikashvili, under the leadership of Z. Javakhishvili. The map compiles a probabilistic measure of seismic hazard, expressed as the long-term mean frequency of seismic shaking expected at a given location from all sources of earthquakes which occurred in the surrounding area. The map is based on the SSZs model and on a map of seismic activity which actually presents areal variations of the levels of the recurrence plots. For the calculation of ground motion, the mean depth of the seismogenic layer was taken as $H=10 \mathrm{~km}$ and an intensity attenuation law with distance in the form of Shebalin's formula was used. The probabilistic map of seismic hazard is expressed in intensity isolines at fixed ground motion values for a recurrence period of $T=475$ years; zones with intensity $I \geq$ VII and VIII (MSK) and individual areas with $I \geq I X$ are marked in fig. 11 .

Seismic hazard assessment: historicalprobabilistic approach (IG/GAS, Georgia)

The historical-probabilistic map of seismic hazard was compiled by E. Jibladze and N. Butikashvili, using as input the frequency/size distribution from the SCETAC catalogue, the magnitude-dependence of the energy class by Rautian, the macroseismic field parametrization by Blake and Shebalin, the dependence between preparation area and earthquake size (according to Riznichenko and Jibladze), the hazard formulation of Cornell and the ground motion equation by Riznichenko (1965). Seismic hazard was compiled for a return period of $T=475$ years and a waiting time of $t=50$ years, and expressed in terms of macroseismic intensity (fig. 12).

\section{Compatibility of different SHA methodologies}

The different models of seismic hazard assessment obtained by different groups for the 


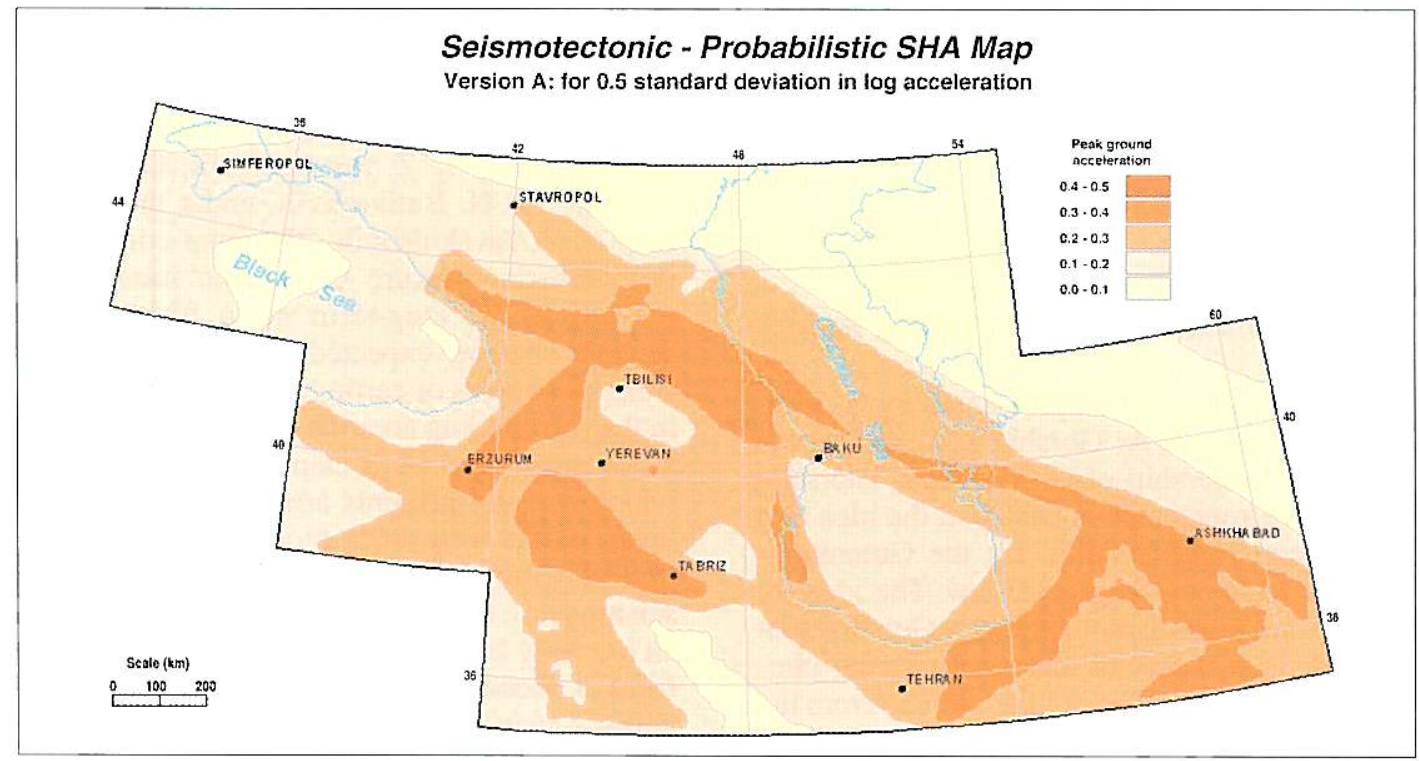

Fig. 5. Seismic hazard map of the Caucasus test area computed using the seismotectonic probabilistic approach and adopting a 0.5 standard deviation to characterize the attenuation uncertainty. Peak ground acceleration expected with a $10 \%$ exceedance probability in 50 years (return period of 475 years) is displayed.

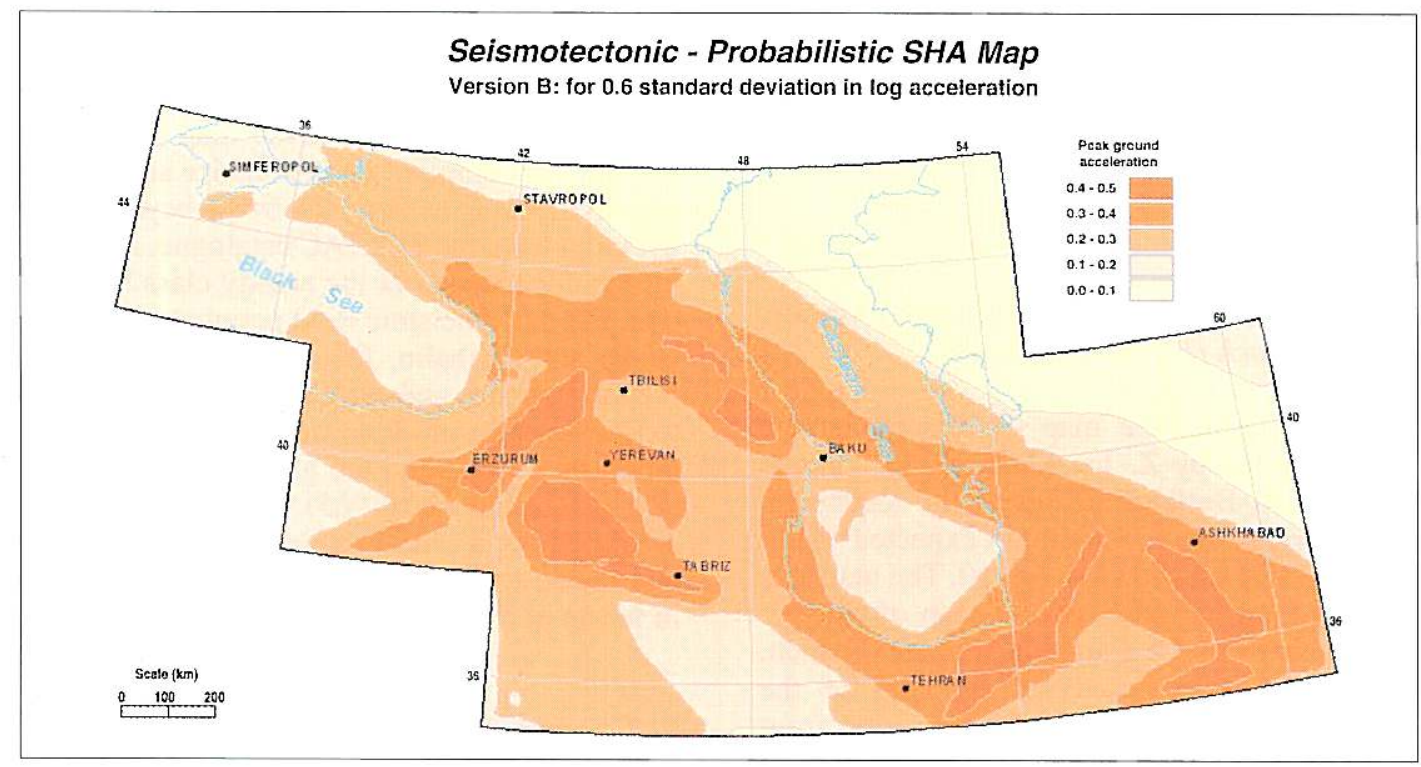

Fig. 6. Seismic hazard map of the Caucasus test area computed using the seismotectonic probabilistic approach and adopting a 0.6 standard deviation to characterize the attenuation uncertainty. Peak ground acceleration expected with a $10 \%$ excecdance probability in 50 years (return period of 475 years) is displayed. 


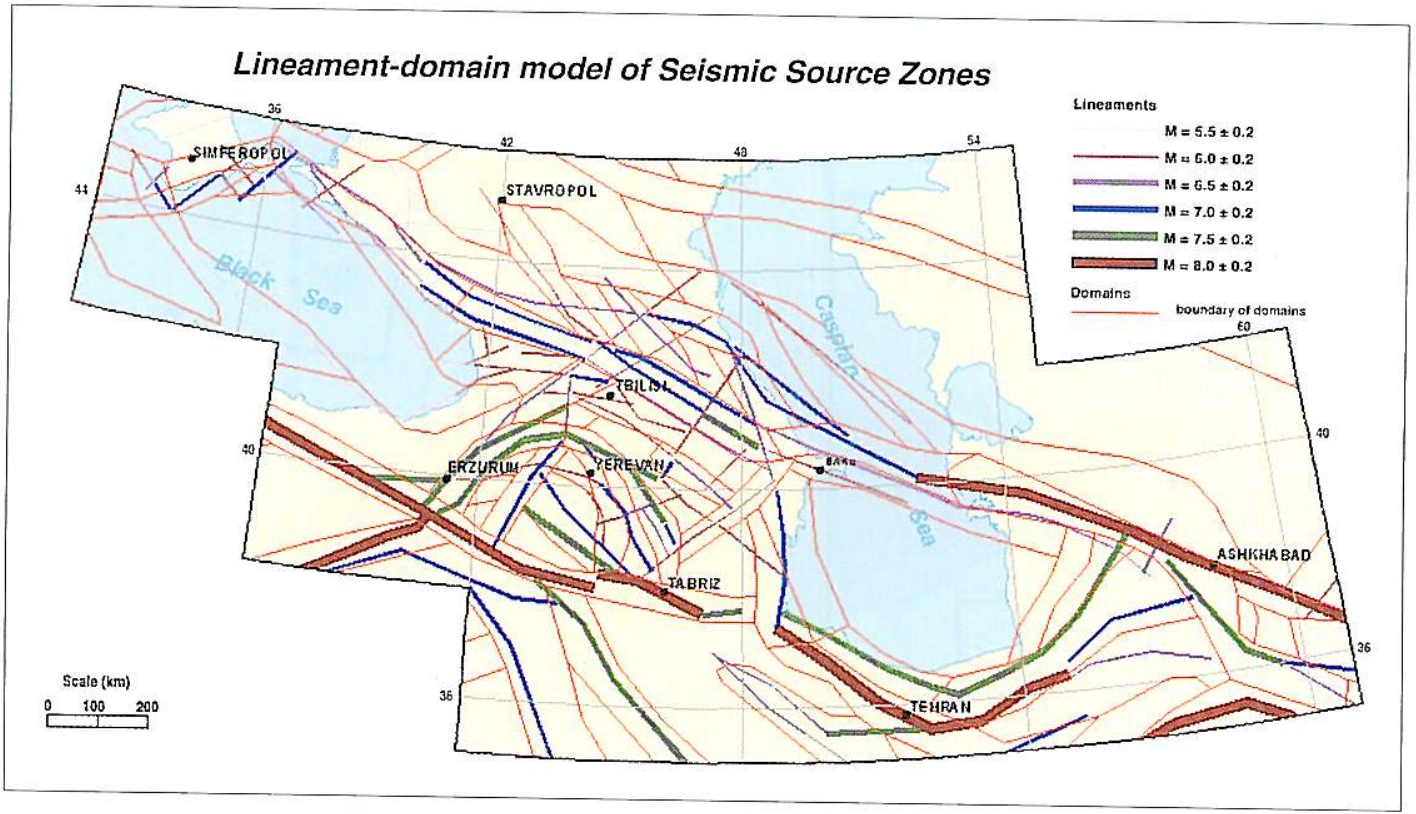

Fig. 7. Lineament-Domain-Focal model (LDF-model), combining three main types of seismogenic structures: lineaments, domains and potential earthquake sources.

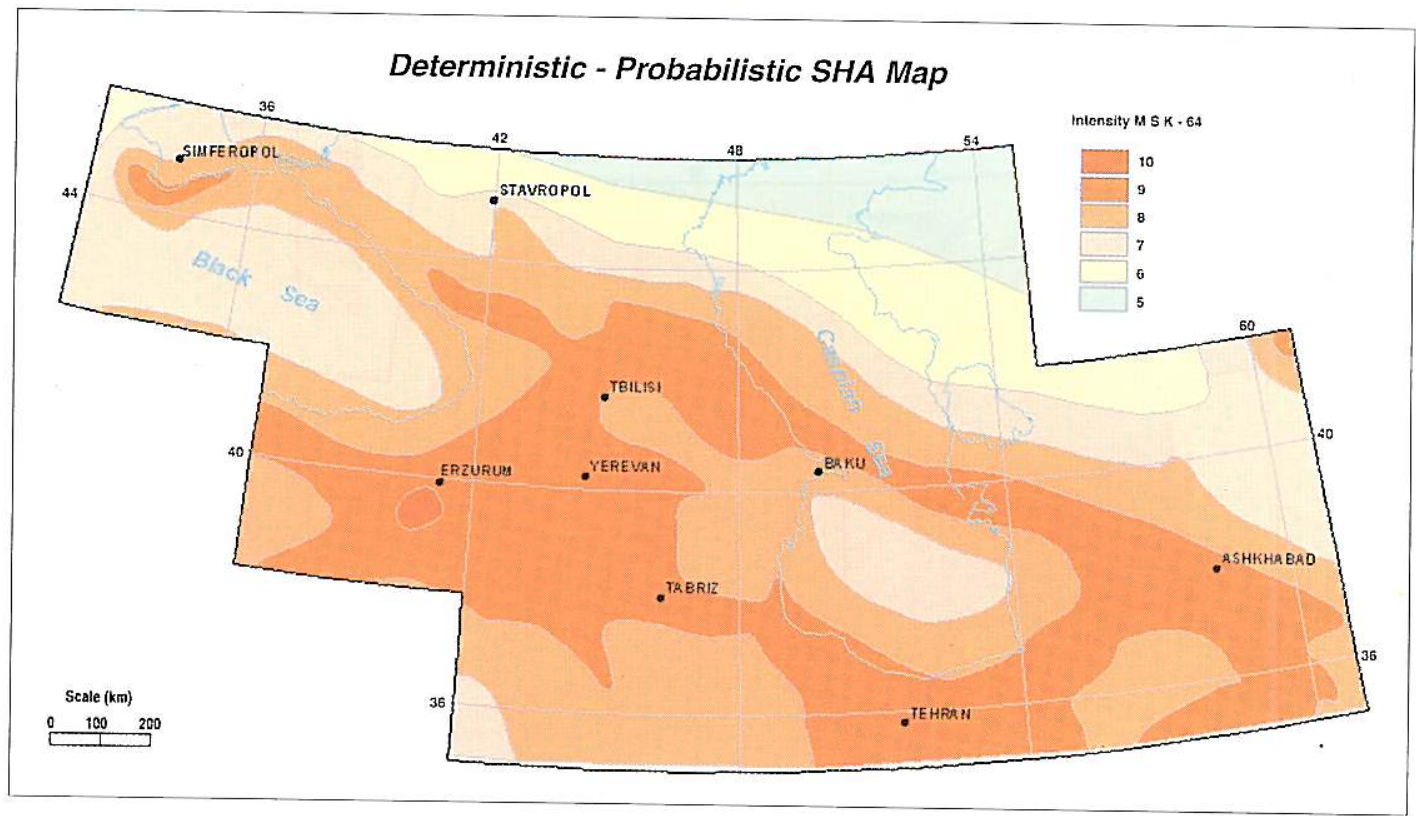

Fig. 8. Seismic hazard map of the Caucasus test area computed using the deterministic-probabilistic approach on the basis of the Lineament-Domain-Focal model (LDF-model) in fig. 7. MSK-64 intensity expected with a $10 \%$ exceedance probability in 50 years (return period of 475 years) is displayed. 


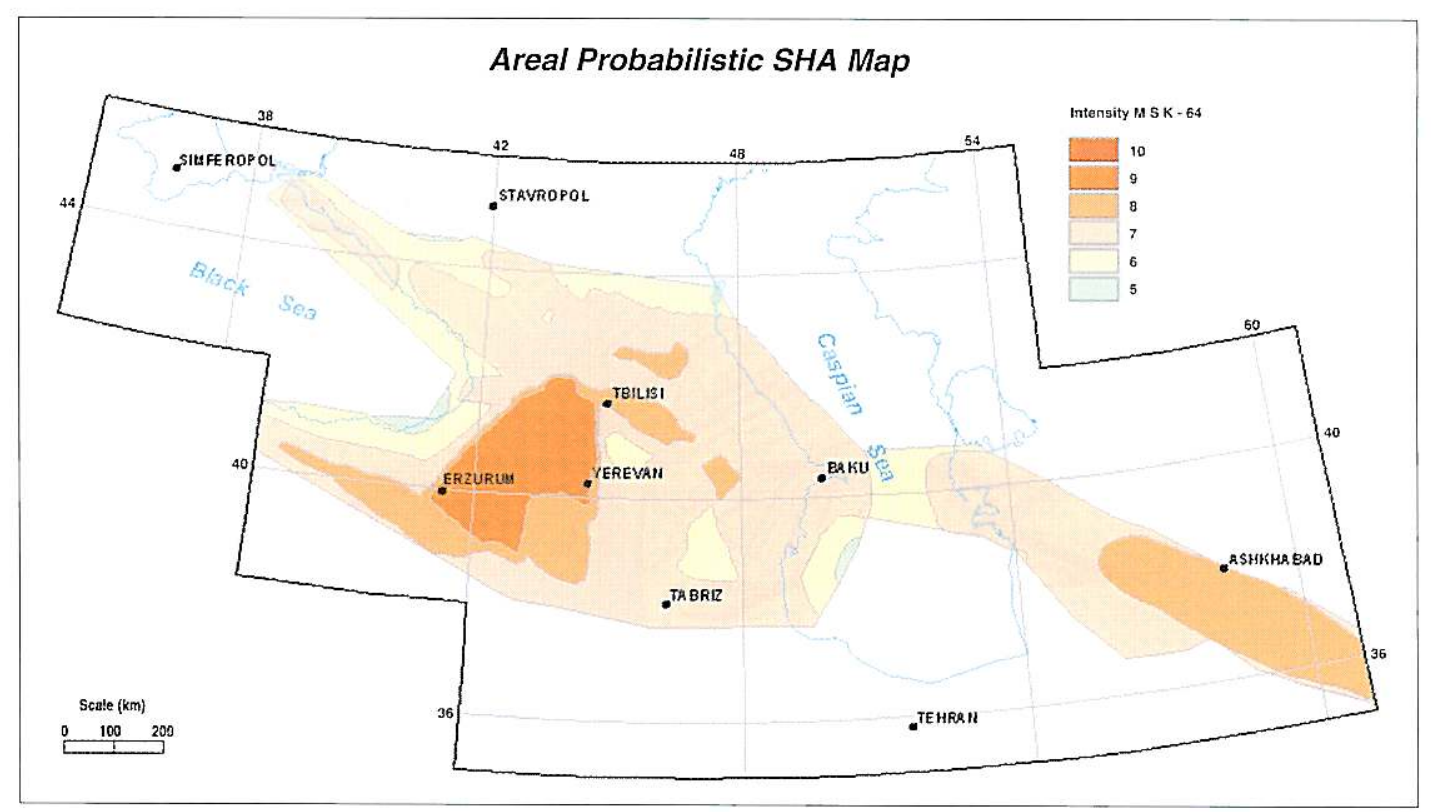

Fig. 9. Seismic hazard map of the Caucasus test area computed using the areal-probabilistic approach. MSK-64 intensity expected with a $10 \%$ exceedance probability in 50 years (return period of 475 years) is displayed.

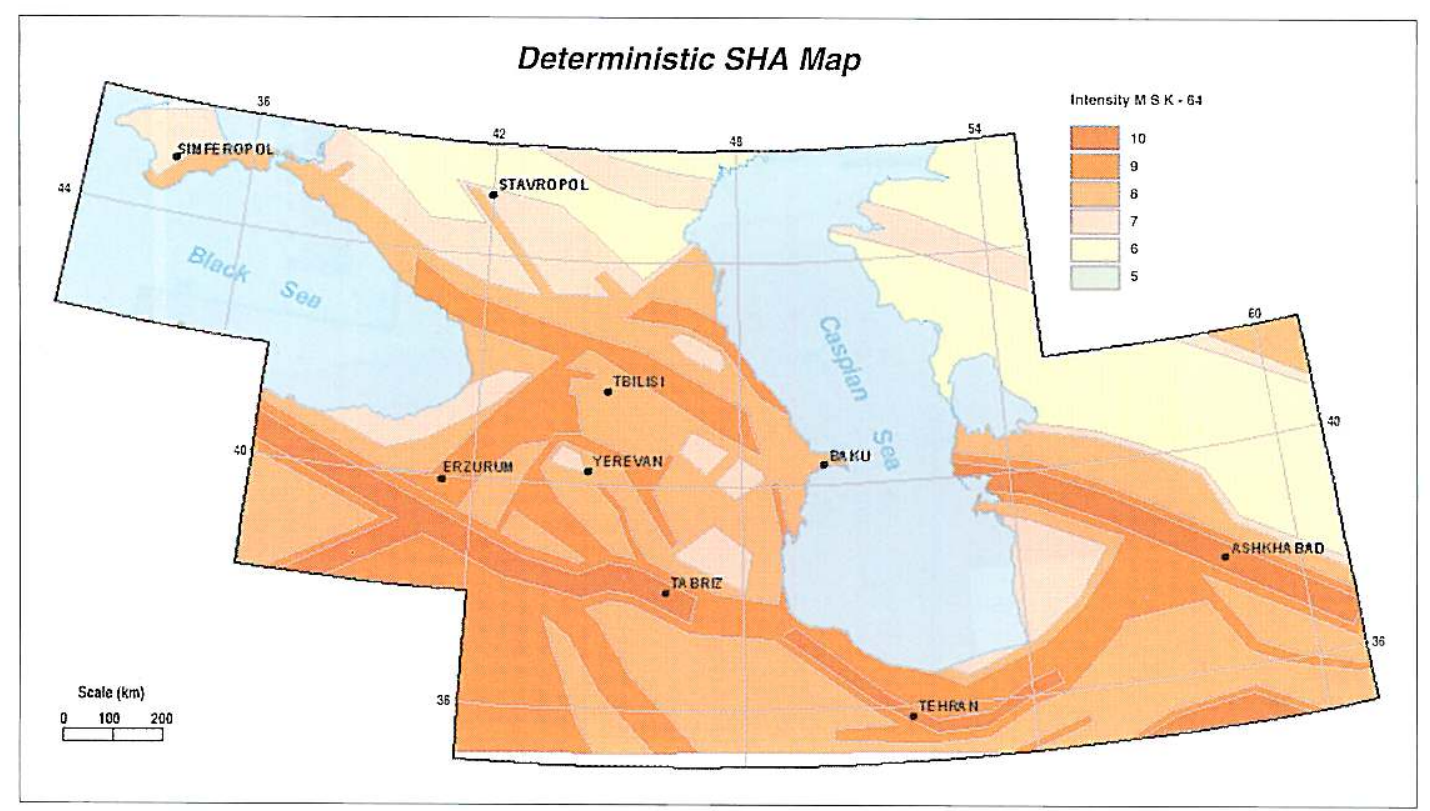

Fig. 10. Seismic hazard map of the Caucasus test area computed using the deterministic approach. Maximum expected MSK-64 intensity is displayed. 


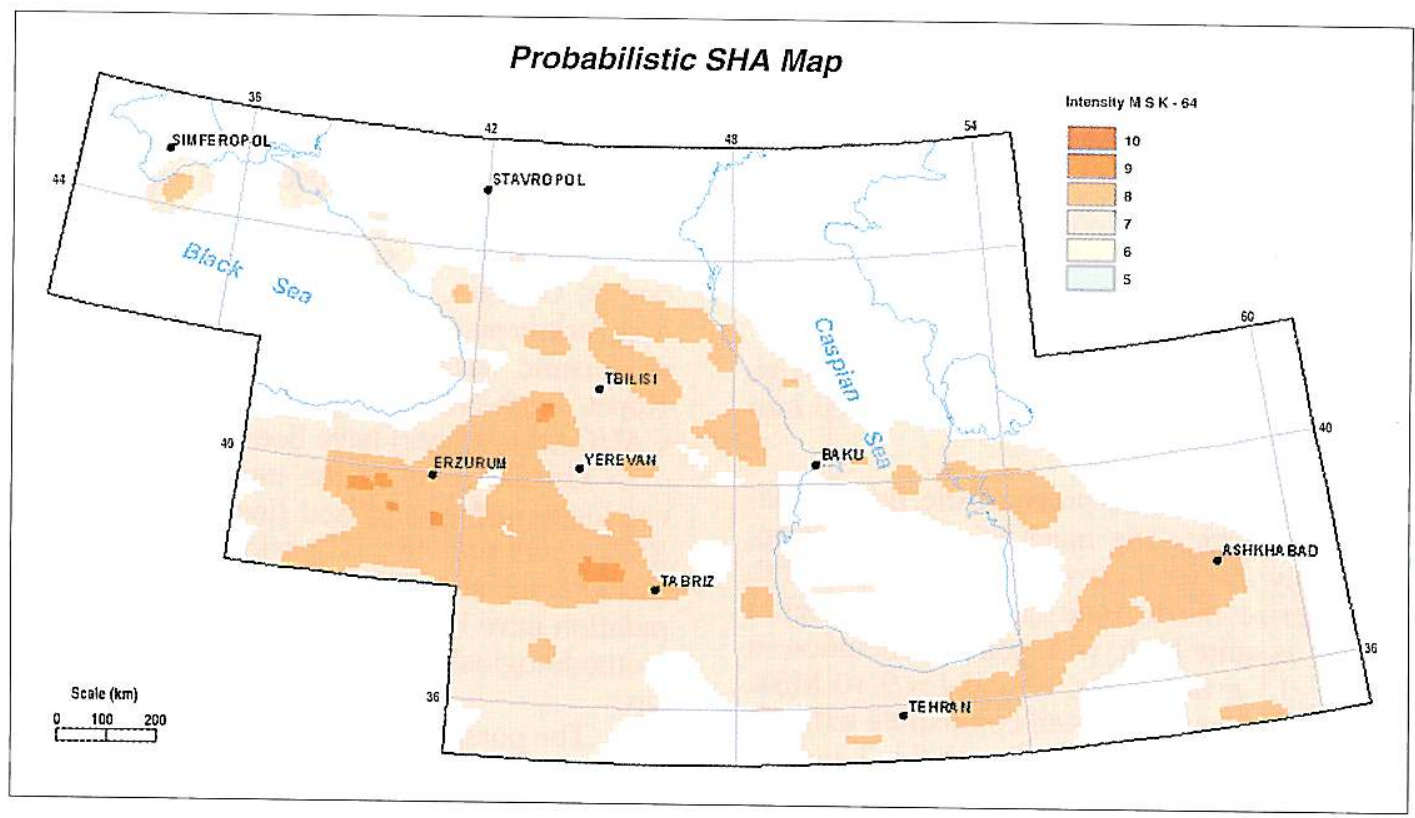

Fig. 11. Seismic hazard map of the Caucasus test area computed using a probabilistic approach. MSK-64 intensity expected with a $10 \%$ exceedance probability in 50 years (return period of 475 years) is displayed.

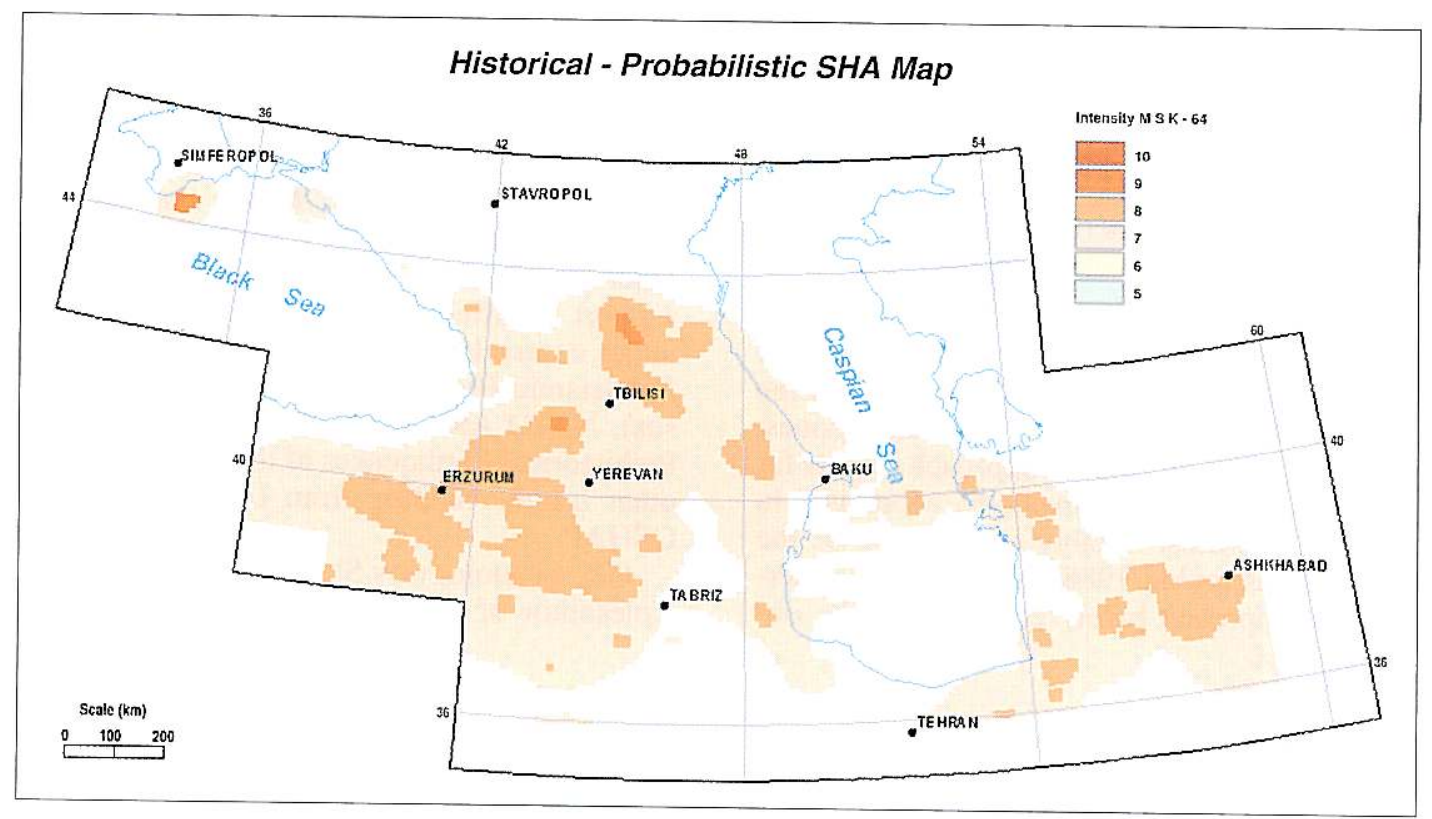

Fig. 12. Seismic hazard map of the Caucasus test area computed using the historical-probabilistic approach. MSK-64 intensity expected with a 10\% exceedance probability in 50 years (return period of 475 years) is displayed. 
CAUCAS test area were summarised. These can be compared by three characteristics:

- The value of the maximum seismic hazard expressed in intensity of MSK-scale, or in peakground acceleration.

- The contours of zones with different value of seismic hazard.

- The correspondence of the hazard maps to values observed in recent years.

By all these characteristics the SHA maps, obtained by different methods, are divided into three groups:

1) Seismotectonic-probabilistic, deterministic-probabilistic. The maps of the first group, especially the versions shown in figs. 6 and 8, characterize the seismic hazard in the region mostly as quite high, with peak acceleration in the 0.3-0.5 $g$ range (fig. 6) and $I=9-10 \mathrm{MSK}$ (fig. 8). Both maps are well compatible with the observed strong seismic events in fig. 3 and the known active structures fig. 4.

2) Areal-probabilistic, probabilistic, historical-probabilistic. The second group of methods shows quite similar results (the areal method covers a smaller area) and depicts generally low hazard for the region (figs. 9, 11 and 12), with typical $I=7 \mathrm{MSK}$ high values for similar areas in the three maps. All three maps map the location well, but not the intensity, of observed past strong earthquakes (fig. 3), and do not reflect active seismotectonics (fig. 4) which is needed to produce future strong earthquakes.

3) Deterministic (fig. 10). The deterministic map is closer to the 1st group than the 2 nd both for maximum value of seismic hazard and the configuration of seismically hazardous zones. However, the deterministic approach is quite far from the 1st group of methods. Moreover, in some cases (most notably in the area of the Spitak catastrophe, $1988, M=7.0$ ) the deterministic approach barely conforms to the observed data.

\section{Conclusions}

The work implemented in the framework of the IASPEI-GSHAP-INTAS «Test Area for Seismic Hazard Assessment in the Caucasus» pro- gramme (INTAS Ct.94-1644) demonstrated the feasibility and importance of the GSHAP concept.

- Based on the consensus achieved between the national groups of specialists representing the responsible seismological surveys of Caucasian and adjacent countries (Armenia, Azerbaijan, Georgia, Turkey, Iran, Russia, Ukraine and Turkmenistan), the first databases and maps of seismic hazard for the Crimea-CaucasusKopet Dagh-NE Turkey-NW Iran region (the CAUCAS test area) have been compiled.

- On the basis of the unified «SCETAC» catalogue and generalised lineament model of SSZs, common to all participants, different methods and approaches to seismic hazard computation have been used, representing different methodological schools present in the Caucasus.

- The possibility of comparison of different methods and approaches of western and eastern standards toward SHA using the common data base, small scale of zonation and duration of a return period, has been shown.

\section{Acknowledgements}

The authors are grateful to all scientists from the countries of Western Europe, FSU, as well as Iran and Turkey who took part in the implementation of this project. We are also thankful to INTAS, GSHAP, NATO, IASPEI and all the other organizations who provided the financial support at different stages of implementation, under contracts INTAS Ct.94-1644 (Test Area for Seismic Hazard Assessment in the Caucasus), NATO ARW Ct.95-1521 (Historical and Prehistorical Earthquakes of the Caucasus), and other $a d-h o c$ funding from IASPEI and ILP/ GSHAP.

GIS technology by Sh. Anderzhanov and Yu. Kolesnikov of UIPE, Moscow.

\section{REFERENCES}

BEnder, B. and D. PERKINS (1987): SEISRISK III. A computer program for seismic hazard estimation, USGS Bulletin No.1772.

BuNE, V.I. and G.P. GoRshKov (Editors) (1980): Seismic Zoning of the Territory of the USSR (Nauka, Moscow), p. 307. 
CORNELL, C.A. (1968): Engineering seismic risk analysis, Bull. Seismol. Soc. Am., 58, 1583-1906.

GIARDINI, D. and S. BALASSANIAN (1997): Historical and Prehistorical Earthquakes in the Caucasus, edited by D. GIARDINI and S. BALASSANIAN, NATO ASI Series (Kluwer Academic Pub.), vol. 28, pp. 545.

GulKan, P. and M. YuCEMEN (1991): Practice of earthquake hazard assessment in Turkey, Report prepared in relation with the IASPEI-ESC Project on World-Wide Seismic Hazard Applications, Department of Civil Engineering, Department of Statistics, Middle East Technical University, Ankara, Turkey, p. 5.

HANKS, T.C. and H. KANAMORI (1997): A moment magnitude scale, J. Geophys. Res., 84, 2348-2350.

JOYNER, W.B. and D.M. BoORE (1993): Methods of regression analysis of strong motion data, Bull. Seismol. Soc. Am., 83, 469-487.

KaRniK, V., N. Kondorskaya, J. Riznitchenko, E. SAVARENSKY, S. SOLOVIEV, N. SHABLIN, J. VANEK and A. ZATOPEK (1962): Standardization of the earthquake magnitude scale, Studia Geophys. Geod., 6, 41-45.

KEILIS-BOROK, V.I., T.L. KRONROD and G.M. MOLCHAN (1973): Algorithm for the estimation of seismic risk, Comput. Seismol., 6, 1-44.

KondorskayA, N.V. and N.V. SHEBALIN (1982): New Catalogue of the Strong Earthquakes of the USSR from Ancient Times Through 1977, World Data Center A, Colorado.
MoINFAR, A., M. BERBERIAN, M. QORASHI, A. ZOUHRIAN and A. NADERZADEH (1987): Preliminary Seismic Zoning and Earthquake Hazard in Iran for Use in the Iranian Code for Seismic Design of Buildings, Building and Housing Research Center, Ministry of Housing and Urban Development, 74, p. 35 (in Farsi).

RAUTIAN, T.G. (1960): Earthquake energy transaction, JIPE, 9, 35-114.

RIZNICHENKO, YU.V. (1965): From the activity of seismic sources to the intensity recurrence at the ground surface, Izv. AN SSSR, Fizika Zemli, 11, 1-12 (in Russian).

SHEBALIN, N.V. and R.E. TATEVossian (1997): Catalogue of strong earthquakes $(M \geq 6.0)$ for the Global Seismic Hazard Assessment Program: test area of Caucasus, in Historical and Prehistorical Earthquakes in the Caucasus, editors D. GIARDINI and S. BALASSANIAN, NATO ASI Series (Kluwer Academic Pub.), 1-32.

TRIFONOV, V.G. and M.N. MACHETTE (1993): The world map of major active faults project, Ann. Geofis., 36 (3-4), 225-236.

Ulomov, V.I., L. SHumilina, V. TRIFONOV, T. KRONROD, K. LEVI, N. ZHALKOVSKY, V. IMAEV, A. IVASTCHENKO, V. Smirnov, A. Gusev, S. Balassanian, A. GassaNov, R. Ayzberg, T. Chelidze, A. Kurskeev, A. Turdukulov, A. Drumya, S. Negmatullaev, T. ASHIROV, B. PustovitenKo and K. AbDullabeKov (1999): Seismic hazard of Northern Eurąsia, Ann. Geofis., 42 (6), 1023-1038 (this volume). 